\title{
0 monitoramento do correio eletrônico no ambiente de trabalho
}

The monitoring of electronic mail in the working environment

\author{
Lígia Maria Deganello ${ }^{1}$ \\ Lourival José de Oliveira ${ }^{2}$
}

\begin{abstract}
Resumo
Analisou-se a possibilidade do monitoramento do correio eletrônico pelo empregador no ambiente de trabalho e colocou-se em debate a questão do controle patronal frente às novas relações oriundas da globalização num paralelo entre vida privada e poder diretivo do empregador. Observou-se que o monitoramento deve ser utilizado como último recurso, respeitando em todo caso, a adequação entre 0 procedimento utilizado e o propósito almejado. Verificou-se a possibilidade do email corporativo se submeter a um controle formal e em casos de indícios de abuso, a um controle material, com comunicação prévia do afetado, permitindo-se um controle meramente formal sobre o e-mail particular, que somente em casos excepcionais e através de autorização judicial ou do prório empregado pode ter 0 seu conteúdo monitorado. Ponderou-se pela vigilância razoável sobre os meios de comunicação, observando a função social da propriedade e o equilíbrio dos direitos envolvidos, sob pena de ensejar em assédio moral, dano moral e rescisão indireta do contrato de trabalho. Por fim, apontou-se a importância da negociação coletiva, do regulamento interno e da política empresarial de uso dos meios de comunicação como formas de pacificar o conflito.
\end{abstract}

Palavras Chave: Monitoramento do correio eletrônico; Poder diretivo do empregador; Privacidade; Padrão razoável de vigilância.

\begin{abstract}
It was analyzed the possibility of tracking the mail by the employer in the workplace and put themselves in the issue of employer control forward to the new relations of globalization from a parallel between privacy and power steering of the employer. It was observed that the monitoring should be used as a last resort, while in any case, the adequacy of the procedure used and the purpose sought. There was the possibility of corporate e-mail is subjected to a formal and in cases of evidence of abuse, a control material, with notification of affected, so is a purely formal control over the particular e-mail, which only in exceptional cases and through his own judicial authorization or the employee may have its content monitored. It is considered reasonable by monitoring the media, observing the social function of property and balance the rights involved, under penalty of rise in bullying, moral and indirect termination of employment. Finally, pointed to the importance of collective
\end{abstract}

${ }^{1}$ Graduada do curso de Direito da Universidade Estadual de Londrina.

${ }^{2}$ Doutor em Direito (PUC-SP); professor associado da Universidade Estadual de Londrina; professor da FACCAR; professor do curso de M estrado em Direito da UNIM AR.

ReVISTA de Direito Púbuco, LondRINA, V, 4, N. 2, P. 172-194, M Aio/ Ago. 2009. 
bargaining, the rules of business and politics use the media as a means of pacifying the conflict.

Keywords: Monitoring of electronic mail; The employer's power steering; Privacy; Reasonable tandard of supervision.

\section{Introdução}

0 advento da revolução tecnológica propiciada pelo fenômeno da globalização ocasionou significativas mudanças nas relações de trabalho, sobretudo com a introdução da informática no meio de produção corporativo.

Diante da facilidade na interação, da rapidez no acesso às informações, da simplicidade de manuseio, a internet e o correio eletrônico passaram a substituir gradativamente os antigos instrumentos de comunicação, sendo atualmente, ferramentas indispensáveis ao desempenho das atividades laborais.

Todavia, ao lado da racionalização do trabalho, do aumento da produtividade, do incremento dos meios de produção e da celeridade na prestação de serviços, a expansão do uso da internet no ambiente corporativo permitiu, por via reflexa, a ampliação do poder diretivo do empregador, tornando tênue a fronteira existente entre a vida privada e trabalho.

A ausência de legislação específica e a inexistência de uma linha jurisprudencial consolidada sobre a matéria têm intensificado os debates em torno da legalidade do monitoramento dos correios eletrônicos e dos sites acessados pelos empregados durante a jornada de trabalho, ainda mais em razão da larga utilização dos meios de comunicação para fins diversos da atividade profissional.

Nessa seara, poderia o empregador controlar o acesso à internet e ao correio eletrônico utilizado pelo empregado durante a jornada de trabalho? 0 empregado, sob 0 fundamento do direito à privacidade, poderia impedir o gerenciamento eletrônico? 0 e-mail possui as garantias de sigilo, privacidade e inviolabilidade inerente à correspondência postal? Pode o empregado usar o e-mail para comunicação com o sindicato de sua categoria?

A partir dessas indagações é que se procurará desenvolver o tema do presente trabalho, analisando em especial, os aspectos que envolvem o correio eletrônico, os limites 
de vigilância do empregador, as condições que justificam a impossibilidade e a legalidade do monitoramento, a viabilidade de controle dos e-mails, os danos ocasionados pela fiscalização indiscriminada, a importância da negociação coletiva de trabalho, do regulamento interno da empresa e da política empresarial de uso dos equipamentos de informática como formas de estabelecer diretrizes para a utilização da internet e do correio eletrônico no ambiente laboral.

\section{As novas tecnologias nas relações laborais: breve análise}

Diferentemente da sociedade industrial, em que o labor exigia o trabalho manual do empregado operante da máquina, a sociedade pós-industrial é marcada pela automação e pelo aperfeiçoamento das novas tecnologias de informação e comunicação (BELM ONTE, 2004, p, 16).

Ocorre que o desenvolvimento da tecnologia desencadeou a chamada terceira Revolução Industrial, que introduziu o modelo toyotista como novo sistema de produção, onde se prepondera "a sofisticação da máquina", a maior flexibilidade, como a "subordinação à distância", surgindo outros meios de controle, como o "teletrabalho", "as decisões tomadas em conjunto", priorizando pela a "terceirização" e pelo "modelo de produção sem estoques" (BELTRAN, 2005, p. 19).

Assim, por conseqüência da globalização e da revolução tecnológica do período pós-industrial houve significativas modificações no ambiente laboral, tais como: desemprego, substituição do homem pela máquina, exclusão social, crescimento do mercado informal, do trabalho parassubordinado, automatização da mão-de-obra, redução da necessidade de trabalhadores, greves, diminuição dos custos da produção e quebra das barreiras temporais e espaciais de trabalho (BELM ONTE, 2004, p. 20).

Ao analisar os efeitos da globalização nas relações jurídicas de trabalho Belmonte observa que:

Hoje, 0 ambiente de trabal ho é diferente daquele em que as normas trabal histas protetivas tiveram a sua gestação: a sociedade - globalizada, diga-se - busca a eficiência econômica em um ambiente racional no qual é indispensável a utilização de novas ferramentas de trabalho, que operam no pressuposto do conhecimento continuado e sem a necessidade da presença física do trabalhador (2004, p.13). 
Realmente, a inserção de novas tecnologias de informação, sobretudo no meio ambiente laboral, ocasionou mudanças positivas e negativas na relação entre empregado e empregador. Embora tenha trazido vantagens, tais como a racionalização do trabalho e 0 aumento da produtividade da empresa, a informatização, de outro lado, ampliou o exercício do poder diretivo do empregador, restringiu 0 direito à privacidade do empregado $\mathrm{e}$ acarretou sérias desvantagens de ordem profissional, econômica e social (LEAL JÚNIOR; GAШINA, 2007).

0 uso da internet como ferramenta de trabalho

A internet configura-se como uma tecnologia recente e essencial para o desenvolvimento das atividades habituais, inclusive àquelas ligadas ao âmbito empresarial, dado a sua rapidez e facilidade no acesso a informações.

Em razão das inúmeras vantagens que possuí sobre outros meios de comunicação, tais como rapidez na interação e informação, baixo custo de manutenção, simplicidade no manuseio, economia de tempo e papel, facilidade no arquivo e envio de mensagens, a internet e o e-mail, substituíram os meios antigos de comunicação e passaram a ser utilizados como ferramentas indispensáveis no ambiente corporativo (PAIVA, 2002).

De fato, a intensa presença da informática e da globalização no cotidiano das pessoas e das empresas em geral, levou estas últimas a utilizar a internet e o correio eletrônico como forma de reestruturar o processo produtivo, aumentar a produtividade, simplificar os procedimentos corporativos, facilitar a comunicação profissional, racionalizar o trabalho e desenvolver com mais eficiência e celeridade as suas atividades, alterando sobremaneira as relações laborais.

Ainda, na esteira das novas tecnologias, além da internet, as empresas passaram a utilizar a intranet, rede corporativa voltada para a comunicação do público interno da empresa, e a extranet, rede corporativa voltada para a comunicação externa da empresa, como forma de simplificar a interação, agilizar o serviço e tornar mais dinâmico e eficiente o desenvolvimento das atividades empresariais (OLIVEIRA, 2005, p. 231).

Em contrapartida, apesar das facilidades proporcionadas pela tecnologia, há casos em que o seu uso inadequado pode gerar danos, como ocorre com o e-mail, que utilizado indevidamente pelo empregado pode colocar em risco a segurança e o bom andamento da 
empresa, razão pela qual muito se tem discutido sobre a possibilidade do empregador controlar, através do monitoramento, o bom uso do aparato eletrônico colocado à disposição do empregado, bem como a abrangência e os limites do poder diretivo do empregador, objeto do presente estudo.

\section{Correio eletrônico}

Em termos práticos, o correio eletrônico consiste numa forma de transmissão de informações à distância por meio de uma rede de comunicações, configurando-se assim, como um dos recursos mais utilizados na internet.

Por seu turno, Pereira explica que em uma primeira visão poder-se-ia afirmar que "o e-mail é a versão informática do conhecido e tradicional correio postal", sendo, contudo, dotado de características e particularidades próprias (2004, p. 58).

A isso, Paiva (2002) acrescenta:

O e-mail pode ser concebido como um mecanismo disposto por meio eletrônico que tem como finalidade principal a transmissão de conteúdo à distância. É um sistema mediante 0 qual se pode enviar e receber mensagens de uma caixa de correio de uma pessoa até a caixa de correio de outra permitindo a emissão e recepção de mensagens. É um meio utilizado para enviar mensagens escritas de um computador a outro através da rede, um equivalente eletrônico do correio convencional com papel, pelo qual as pessoas podem enviar mensagens a um receptor, ou a vários receptores simultaneamente.

Desse modo, pode-se dizer que o correio eletrônico funciona como um meio de comunicação que se opera pela transmissão de mensagens através de uma rede de comunicação onde o usuário possui o seu próprio endereço.

\section{Natureza Jurídica}

Inicialmente, vale lembrar que a definição da natureza jurídica do e-mail não se acha pacificada na doutrina e na jurisprudência, pois ainda permanecem divergências quanto a sua equiparação à correspondência postal.

Sob a ótica de Ferreira, o e-mail não possui natureza de correspondência postal, pois o intercâmbio de mensagens eletrônicas não se enquadra nas disposições legais que 
regulam o serviço postal (art. 21, inc. X CF CC arts. $2^{\circ}$ e $7^{\circ}$ da Lei $n^{\circ} 6.538 / 78$ ), não se submetendo, por derradeiro, à competência da União (2003, p. 16).

Para a ilustre jurista, a correspondência eletrônica detém características próprias, tais como o meio de circulação, que não permitem a sua equiparação à postal (2003, p. 16).

Por ser a internet um ambiente aberto, Ferreira (2003, p. 16) ainda explica que:

\begin{abstract}
Aplicando uma interpretação analógica, poder-se-ia considerar que a correspondência fechada corresponde a uma mensagem eletrônica que trafega sem qualquer mecanismo de segurança que impossibilite 0 acesso por terceiros não autorizados. Traçando-se um paralelo, a correspondência eletrônica encontraria alguma semelhança com a definição de cartão postal, uma vez que a mensagem circula na rede despojada de qualquer envoltório ou lacre, vale dizer em termos tecnológicos, sem nenhuma proteção ou segurança.
\end{abstract}

Em relação à natureza da correspondência eletrônica, verifica-se que o conteúdo do e-mail corporativo disponibilizado pela empresa possui natureza comercial, portanto, não submetido às disposições constitucionais que asseguram o sigilo das correspondências: "nesse caso o sigilo que merece proteção se opera em favor do proprietário da ferramenta de trabalho e se dirige às informações sigilosas da empresa". Por outro lado, no que diz respeito ao e-mail pessoal, a tutela à privacidade deve-se em razão da esfera íntima do seu titular (FERREIRA, 2003, p. 16).

Em contrapartida, numa posição intermediária há quem entenda que o correio eletrônico possui natureza sui generis.

Já para Paiva, o correio eletrônico se assemelha ao postal ressalvadas as particularidades inerentes a cada um. Segundo o referido autor, "as diferenças entre as duas comunicações não podem ser consideradas de maneira radical, pois apesar de terem suas peculiaridades ambas devem respeito à ordem legal vigente" (PAIVA, 2002).

Acertadamente, Paiva (2002) afirma que a legislação destinada ao correio postal deve ser analisada e aplicada diferentemente ao correio eletrônico, haja vista que alguns fatores, tais como as condições de envio e a propriedade dos meios utilizados, não podem ser considerados para ambos de forma análoga.

Assim, embora o correio eletrônico tenha natureza controvertida, a posição que permite uma solução mais coerente para o sistema e melhor se adapta à nova realidade é a que o considera como correspondência assemelhada à postal, "sendo passível de proteção 
direta pelo sigilo das comunicações e indiretamente, pelo direito à intimidade" (BELM ONTE, 2004, p. 66).

\section{Correio Eletrônico Corporativo}

A correspondência eletrônica, dependendo da titularidade do endereço eletrônico, distingue-se em pessoal (convencional) ou corporativa (institucional).

Sobre o correio eletrônico corporativo é oportuno ressaltar o entendimento de Ferreira (2003, p. 16):

[...] o endereço eletrônico pertence à conta corporativa atua como veículo de comunicação privada do empregador e integra seu ambiente privado. 0 correio eletrônico corporativo traduz-se em um serviço de correio interno e privativo da empresa, voltado exclusivamente para o exercício de sua atividade comercial [...].

Assim, o e-mail corporativo, fornecido em virtude do vinculo empregatício firmado, é utilizado em nome da empresa, funcionando como um verdadeiro instrumento de trabalho destinado ao uso estritamente profissional e ao tráfego de informações referentes, em sua essência, às atividades corporativas, não estando, confome dito, sujeito ao amparo constitucional que resguarda a intimidade e a inviolabilidade das correspondências. Nesse sentido, esclarece Ferreira (2003, p. 18):

Ao determinar e fornecer o login e senha de conexão ao funcionário, a empresa outorga um direito de acesso a seu ativo de informação, que se constitui em um privilégio associado a um cargo, pessoa ou processo, que não se destina, comporta ou autoriza o trânsito de dados pessoais, informações sensíveis ou íntimas do funcionário (2003, p.18).

Tanto é assim que, com o término do pacto laboral, o e-mail do ex - empregado deve ser desativado e o conteúdo das mensagens deve ser repassado para a empresa, verdadeira proprietária da correspondência (CARNEIRO, 2007, p. 91).

\section{Correio Eletrônico Particular}

Pretende-se expor de maneira sucinta o que se entende por correio eletrônico pessoal, uma vez que o seu conceito já é simples e de amplo conhecimento da sociedade 
atual.

No que se refere ao e-mail particular, Ferreira observa que:

\begin{abstract}
Na conta de correio eletrônico particular é a pessoa física quem contrata os serviços de um provedor de acesso, com a finalidade de criar um endereço eletrônico pessoal. Nesse caso, cabe a ela determinar a expressão que deseja adotar em seu endereço, eleger seu próprio login e respectiva senha para acesso. Portanto, a comunicação se realiza através de conta privada do usuário - que detém a titularidade e suporta com todos seus custos da prestação de serviço do provimento de acesso e conexão (2003, p.20).
\end{abstract}

Nessa linha, a referida jurista acrescenta que "a conta pessoal insere-se em inquestionável ambiente de privacidade absoluta do seu titular, uma vez que as informações trafegadas são de natureza pessoal, confidencial e de seu interesse específico " (FERREIRA, 2003, p. 20). Trata-se de uma conta privada de titularidade do usuário do sistema, sendo pois, inviolável quanto ao seu conteúdo.

\title{
Monitoramento do correio eletrônico
}

As empresas, em razão da utilização do correio eletrônico pelo empregado para fins não relacionados ao serviço, passaram a utilizar o monitoramento das mensagens recebidas e expedidas pelos empregados através do correio eletrônico e dos sites visitados durante a jornada de trabalho, como forma de zelar pelo bom uso do aparato eletrônico disponibilizado para o exercício da atividade laboral.

Em síntese, o monitoramento é um meio de dirigir, acompanhar, analisar, controlar e avaliar uma ação ou um evento, através de dados fornecidos por uma aparelhagem técnica (FERREIRA, 1999, p. 1359). Consiste, portanto, no ato de supervisionar o comportamento do empregado no ambiente laboral, sendo geralmente utilizado para verificar o regular desempenho do serviço.

$\mathrm{Na}$ internet, há softwares "espiãos" que permitem o gerenciamento da rede. $\mathrm{Na}$ prática, os programas de monitoramento de desktops instalados fisicamente ou remotamente - neste último caso, há um anexo de e-mail com programa que contém um software para monitoramento, o Cavalo de Tróia- têm a capacidade de armazenar cada toque do teclado, permitindo assim, o rastreamento dos e-mails dos empregados (BONSOR). Como bem esclarece Souza: 
0 monitoramento eletrônico é feito através de programas que registram sites visitados por seus funcionários e com que freqüência, bem como filtram, registram, e classificam automaticamente cada palavra que passa pelo e-mails de suas redes [...]. (2000).

Desse modo, nota-se que o rastreamento da correspondência eletrônica pode ser facilmente realizado através de programas específicos que funcionam como filtros destinados a esse fim (OLIVEIRA, 2005, p. 241).

Das razões que justificam a ampla possibilidade e a impossibilidade absoluta do monitoramento

Primeiramente, para justificar a legalidade do monitoramento eletrônico invoca-se que os equipamentos, os programas, o ativo de processamento e a estrutura de utilização do e-mail pertencem à empresa, sendo o custo do sistema suportado pela mesma (SILVEIRA NETO; PAIVA, 2003, p. 21).

Nessa esteira, fundamenta-se que o poder diretivo do empregador e a conseqüente subordinação jurídica do empregado permitem a interceptação das mensagens eletrônicas, já que o e-mail e a internet são colocados à sua disposição como uma ferramenta de trabalho destinada exclusivamente ao serviço (M ISTRONGUE; KERSTEN, 2004, p. 319).

Sustentam ainda, que o monitoramento visa evitar fraudes, disseminação de vírus, abusos sexuais, divulgação de informações preconceituosas, pornográficas, sigilosas ou danosas à empresa, bem como impedir a baixa produtividade, a perda de tempo, o congestionamento do tráfego de informações na rede; e prevenir a prática de atos que comprometam a sua imagem, reputação, honra, fama, patrimônio, saúde financeira e integridade perante o mercado econômico (CARNEIRO, 2007, p. 92-95).

Não obstante, os defensores do gerenciamento eletrônico justificam-no também pelo fato de ser a empresa responsável objetivamente pelos atos praticados por seus empregados (art. 932, inc. III e art. 933, ambos do CC), inclusive pelos ilícitos cometidos através da correspondência eletrônica corporativa (SILVEIRA NETO; PAIVA, 2003, p. 21).

Em contrapartida, os principais fundamentos que justificam a ilegalidade e conseqüente impossibilidade jurídica do monitoramento dos sites acessados e do correio eletrônico no ambiente laboral se referem à proteção a dignidade humana do empregado, 
assim como o seu direito constitucional à intimidade, à vida privada, ao sigilo de correspondência, à liberdade de expressão, pensamento e comunicação.

Os limites de vigilância das comunicações: padrão razoável

O empregador, por meio do seu poder diretivo, pode fixar regras no âmbito empresarial, inclusive no que tange à utilização do correio eletrônico durante a jornada de trabalho.

No entanto, a autonomia organizativa do empresário não é ilimitada, pois o seu exercício não pode ignorar os princípios da boa-fé, da dignidade humana, da privacidade do empregado, do sigilo das correspondências, da autonomia das partes e da diligência profissional que permeia as relações laborais, pois atrelado à conduta abusiva do empregador na fiscalização dos sites e e-mails acessados pelos empregados está a figura do assédio moral, que pode ensejar na rescisão indireta do contrato de trabalho pelo ofendido além da reparação por danos morais (ROCHA, 2004, p. 115).

No que se refere aos direitos envolvidos na relação laboral, nota-se que não há direitos absolutos. De um lado, o empregado não pode invocar a inviolabilidade irrestrita das suas comunicações e de outro, o empregador não pode invocar o poder diretivo como forma de autorizar uma intromissão indiscriminada na correspondência eletrônica dos obreiros (ROCHA, 2004, p. 119).

Tendo em vista a ausência de legislação específica que discipline a matéria, a pacificação da questão envolve o equilíbrio de ambos direitos, isto é, a harmonia e proporcionalidade de cada um deles (SILVEIRA NETO; PAIVA, 2003, p. 23).

A essa idéia, Fragale sugere a possibilidade de estabelecimento de um padrão razoável de vigilância no uso da internet e do correio eletrônico no ambiente de trabalho como forma de conciliar os princípios envolvidos (apud BELM ONTE, 2004, p. 75).

De tal sorte, para não ser considerado arbitrário e ofensivo aos direitos fundamentais dos obreiros faz-se necessário esclarecer os objetivos do monitoramento e comprovar a sua real necessidade, devendo sempre observar a dignidade do trabalhador adequando, para tanto, o meio e o procedimento utilizado aos fins pretendidos, sob pena de configurar desvio de finalidade (BELM ONTE, 2004, p. 75-76). 
Ressalta-se, nesse contexto, o dever de se dar prioridade aos instrumentos de controle alternativos e menos ofensivos aos direitos obreiros, tais como bloqueadores de acesso e programas que impeçam o encaminhamento de mensagens a endereços não cadastrados, de modo que o monitoramento seja utilizado como último recurso em casos de abuso (DUARTE; TUPINAM BÁ, 2002, p. 237).

\section{Da Contraposição dos Direitos Envolvidos}

Apreciando a questão do poder patronal e dos bem jurídicos protegidos a nível constitucional, verifica-se que o monitoramento de e-mails envolve posições divergentes aptas a ensejar choque de direitos: de um lado a intimidade e a inviolabilidade de correspondência do empregado e de outro, o poder diretivo do empregador (DINIZ apud BELM ONTE, 2004, p. 72).

Para Clève e Freire, o princípio da proporcionalidade - bem como os princípios da adequação, necessidade, e proporcionalidade em sentido estrito - e o método de ponderação de bens, conferem soluções para a colisão entre os direitos fundamentais (2003, p. 243).

A par disso, a resolução dos conflitos entre os princípios reclama ainda a aplicação do princípio da concordância prática, "que imprime coordenação necessária e efetivação concomitante dos bens em jogo", e da unidade da Constituição, que "clama otimização eficacial a ambos os bens" impondo uma interpretação sistemática dos diversos preceitos constitucionais (CLĖVE; FREIRE, 2003, p. 242).

Isso se dá pelo fato de que a incompatibilidade entre princípios, diferentemente das regras, não exclui o princípio conflitante do ordenamento jurídico (ESPÍNDOLA, 2002, p. 74). É que "os princípios têm um peso diferente nos casos concretos e que o princípio de maior peso é o que prepondera; pois se as regras têm que ver com a validade, os princípios têm muito que ver com os valores" (ALEXY apud DUARTE; TUPINAMBÁ, 2002, p. 235).

Vê-se, portanto, que "existindo dois bens jurídicos fundamentais em colisão, será preciso harmonizar a aplicação simultânea ou sacrificar, pela prevalência, um deles em detrimento do outro, para permitir-se a realização do Direito" (GUERRA FILHO apud ARARIPE, 2002, p. 243). 
Enfim, quando em confronto o exercício do poder de direção e a privacidade do empregado, assim como suas manifestações, é necessário buscar um equilíbrio que assegure a efetividade, a harmonia e a proporcionalidade dos direitos envolvidos, buscando a sua máxima concretização com a mínima restrição (BELM ONTE, 2004, p. 72).

\section{E-mail corporativo: controle}

Em razão do emprego inadequado do sistema operacional da empresa colocado à disposição dos funcionários, o gerenciamento eletrônico feito de forma sensata configura-se como medida preventiva de segurança e proteção contra atitudes desleais do trabalhador que possam implicar em risco e responsabilidade para a empresa.

0 e-mail corporativo, por ser aquele posto à disposição do empregado para ser utilizado em prol do serviço, não possui a inviolabilidade e confidencialidade conferida ao email particular, podendo se submeter a um controle material (BELM ONTE, 2004, p. 85).

Para tanto, há dois tipos de controle eletrônico: o controle formal, que se efetiva por meio de programas, a exemplo dos filtros, que analisam de forma impessoal os aspectos externos da mensagem (título da mensagem, etc); e o controle material, em que se verifica 0 conteúdo da mensagem (ATHENIENSE, 2007).

Assim, independente da existência de cláusula de invasão de privacidade que irá regulamentar, por meio de negociações coletivas, o monitoramento do e-mail corporativo tem a empresa faculdade de fiscalizar e controlar de forma não abusiva o correio eletrônico de titularidade empresarial fornecido ao empregado para uso profissional (BELMONTE, 2004, p. 85).

Entretanto, recomenda-se que essa vigilância se dê, primeiramente, de forma generalizada e impessoal, passando ao controle do conteúdo da mensagem somente em casos de urgência ou de indícios objetivos fundados na suspeita de uso inadequado do equipamento (BELM ONTE, 2004, p. 86-87).

Lembre-se, que a má utilização do computador pelo empregado pode configurar mau procedimento para a dispensa por justa causa do empregado (art. 482, alínea b da CLT) caso a falta não seja tipificada por outro motivo elencado no rol do dispositivo supra (M ARTINS, 2007, p. 359) 
Para que haja o rastreamento eletrônico, Paiva sustenta que deve haver uma comunicação prévia do afetado para essa vasculha, além da presença de um representante sindical que garanta a transparência de todo o procedimento (2002).

Compete ao empregador no uso do seu poder diretivo, esclarecer que o e-mail da empresa é um instrumento de trabalho, que a princípio não pode ser usado para fins particulares, e estabelecer proibições ou limites da sua utilização para fins alheios ao serviço (BELM ONTE, 2004, p. 90).

No entanto, as regras devem ser adaptadas de acordo com o perfil e caracterísitcas de cada empresa, podendo o empregador permitir o uso mínimo do computador para fins particulares fora ou durante o horário de trabalho, inclusive para a transmissão, pela entidade sindical, de informações referentes ao interesse da categoria, desde que de modo justificado, razoável, e sem acarretar prejuízos para a empresa ou queda na produtividade (CARNEIRO, 2007, p. 97). É o que Paiva denomina de uso social do e-mail.

Na visão de Paiva, a adoção do uso racional e não abusivo do e-mail é uma forma de permitir maior liberdade e estímulo para os empregados realizar suas atividades, proporcionando além de qualidade na relação laboral, um ambiente de trabalho confiável e tranquilo (2002).

Observa-se, porém, a obrigação do empregador no sentido de respeitar a privacidade e intimidade obreira caso permita a utilização da internet e do correio eletrônico corporativo para assuntos particulares (DUARTE; TUPINAM BÁ, 2002, p. 238).

Como o correio eletrônico corporativo é passível de controle formal e material pela empresa, para que seja preservada a intimidade do empregado, seria interessante que se criasse além do e-mail profissional, um endereço de e-mail particular disponibilizado pela internet para o trato de assuntos pessoais (CARNEIRO, 2007, p. 98).

Vale lembrar, ao final, que na ausência de expressa definição, é possível que 0 empregado utilize o e-mail corporativo e a internet para fins pessoais, porém em horário apropriado, com bom senso e sem exageros (BELM ONTE, 2004, p. 119). 
E-mail particular: controle

Em relação ao e-mail particular utilizado por meio do equipamento de propriedade do empregador, é possível que haja um monitoramento meramente formal sobre as mensagens com vistas a controlar os abusos na sua utilização (BELM ONTE, 2004, p. 78).

Nada obsta que a empresa no uso do seu poder diretivo, proíba ou restrinja, de modo claro e expresso, a utilização da internet e do correio eletrônico particular durante ou fora da jornada de trabalho, ensejando penas disciplinares para a sua não observância. Contudo, o empregador não pode exercer o controle material do conteúdo das mensagens particulares, sob pena de incorrer em abuso de direito (BELM ONTE, 2004, p. 79).

Em relação ao e-mail pessoal, não há que se falar na cláusula coletiva de invasão de privacidade, pois por veicular assuntos particulares e invioláveis, o conteúdo das mensagens enviadas ou recebidas pelo empregado somente pode ser monitorado por razões circunstanciais relevantes e através de prévia autorização do próprio empregado, sem coação, ou por via judicial, para instrução em processo penal, aplicável extensivamente ao processo civil e trabalhista (BELM ONTE, 2004, p. 79).

Quebra de Sigilo e a Questão da Licitude da Prova Judicial

De início, observa-se que a interpretação literal do artigo $5^{\circ}$, inc. XII da CF pode levar o intérprete a uma conclusão errônea, qual seja a de que a quebra do sigilo com o conseqüente conhecimento do segredo só poderia ocorrer nas comunicações telefônicas.

Em verdade, como nenhuma liberdade individual é absoluta, há circunstâncias pertinentes que no caso concreto podem ensejar na extensão da interceptação a outras hipóteses de comunicação que não só as telefônicas, devendo, pois, ser permitido, em situações justificáveis, o vasculhamento autorizado do e-mail particular do empregado (BELM ONTE, 2004, p. 84).

Isso porque o princípio da proporcionalidade e da prevalência do interesse público permite que o juiz autorize a quebra do sigilo em qualquer tipo de comunicação, pois "Ionge de desproteger, a interpretação extensiva vem justamente impor parâmetros para a obtenção da prova" (BELM ONTE, 2004, p. 84).

Tanto é assim, que a Lei №. 9.296/96 ampliando a aplicação do art. 50, inc. XII CF determina que se aplique à interceptação de comunicações de sistemas de informática e 
telemática a prévia autorização judicial para efeito de prova em investigação criminal e em instrução processual penal (artigo 1ำ par. único), considerando crime a interceptação dessas comunicações sem a referida autorização ou com objetivos não autorizados em lei (art. 10).

A princípio, a prova obtida por meio de uma intervenção desautorizada no e-mail particular obreiro não seria válida para demonstrar a culpa do funcionário, pois a Constituição consigna serem inadmissíveis no processo as provas obtidas por meio ilícito (art. 5, inc. LVI CF), isto é, em desacordo com as regras de direito material.

Entretanto, em casos excepcionais, deve-se admitir a prova ilícita com base no princípio do equilíbrio entre os valores contrastantes e nos critérios da concordância prática, da ponderação de bens, e da teoria da proporcionalidade, pois "admitir uma prova ilícita para um caso de extrema necessidade significa quebrar um princípio geral para atender a uma finalidade excepcional justificável" (CAPEZ, 2006, p. 43-45).

Portanto, a questão deve ser vista com cautela, pois negar a utilização da prova obtida com a transgressão da intimidade alheia, em certos casos, significaria negar o direito de demonstrar fato tão rejeitado pela ordem jurídica quanto à violação à intimidade (BELM ONTE, 2004, p. 82).

Dos danos decorrentes na relação de trabalho

De fato, o liame empregatício rechaça a possibilidade da ocorrência de danos. Com vistas a evitar abusos e resguardar os atributos fundamentais do ser humano, em especial na relação de emprego, admite-se a figura da reparação de danos morais e patrimoniais.

Para a existência de um dano indenizável devem estar presentes os seguintes requisitos: ato ilícito resultante de uma ação ou omissão, dano, com a conseqüente destruição ou redução de um bem jurídico patrimonial ou moral, nexo de causalidade e ausência das excludentes de responsabilidade civil (BELM ONTE, 2004, p. 112).

Releva notar, que o dano tem como ofendido, em regra, o empregado, mas nada obsta que o empregador também o seja, sendo autorizada em qualquer caso, a rescisão do contrato pelo ofendido, sem prejuízo da indenização por danos morais e patrimoniais (NASCIM ENTO, 2004, p. 468). A garantia a essa reparação encontra-se esculpida no art. 5ㅇ, incs. V e X da CF, nos arts. 186 e187 do CC e indiretamente, nos arts. 482, alíneas j e k e 483, alínea e da CLT. 
Desse modo, deslocando a questão da reparação de danos para a esfera do monitoramento eletrônico, nota-se que tanto 0 abuso da vigilância patronal sobre os sites e e-mails dos empregados quanto 0 uso inadequado dos equipamentos de informática de propriedade da empresa por parte dos funcionários - ocasionando fraudes, ofensa à honra e imagem da empresa, por exemplo- pode ensejar em dano moral e/ou patrimonial passível de reparação, sem prejuízo da rescisão do contrato de trabalho.

Além disso, ao lado do dano moral individual o monitoramento desregrado contra determinado segmento da coletividade obreira ofende valores de ordem pública, tais como a dignidade dos trabalhadores e os direitos constitucionais a ele correlatos, podendo ensejar em dano moral coletivo (BARROS, 2007, p. 643).

A negociação coletiva e o regulamento interno: diretrizes para o uso das tecnologias de informática nas relações de trabalho

A norma coletiva produzida através de um processo de negociação coletiva de trabalho constitui-se como método eficaz de solução dos conflitos trabalhistas, visto que é um meio autocompositivo e democrático que permite a harmonização dos interesses profissionais e econômicos envolvidos na relação laboral por meio de atos de transação que importem em concessõ es recíprocas (DELGADO, 2007, p. 1391).

A negociação coletiva configura-se como um instrumento ágil e flexível fundado na autonomia privada coletiva, que tem por fim suprir a insuficiência do contrato individual e estabelecer condições gerais de trabalho (M ARTINS, 2007, p. 787).

Frente à ausência de legislação específica que discipline a questão do monitoramento, faz-se importante e ao mesmo tempo necessário que o uso da internet e do correio eletrônico sejam disciplinados pelos sindicatos através de negociações coletivas para que sejam estabelecidos os critérios de autorização, tolerância ou vedação do uso de equipamentos de informática para fins particulares, observando, em todo caso, as disposições relativas à proteção ao trabalho, os contratos coletivos aplicáveis e as decisões das auto ridades competentes (art. 444 CLT).

As convenções ou acordos coletivos de trabalho, instrumentos resultantes do processo negocial, que tratem do uso do e-mail no ambiente laboral podem versar sobre: 0 uso racional do e-mail corporativo por parte do trabalhador, as condições de acesso a seu 
conteúdo, os limites de vigilância patronal, os casos em que é possível ao empregador obter na esfera judicial a quebra do sigilo, a proteção da privacidade do funcionário, a possibilidade do sindicato e/ou o representante dos empregados manterem uma comunicação de assuntos de interesse sindical através do e-mail corporativo, além de outras situações que abrangem o bom uso do aparato eletrônico da empresa (BELM ONTE, 2004, p. 14). Em todo caso, os termos firmados obrigam as partes contratantes, sob pena de sanção pelo seu descumprimento.

Vale notar que em razão da sua menor abrangência, o acordo coletivo de trabalho atende diretamente as necessidades e situações particulares da empresa acordante, proporcionando assim, uma negociação mais satisfatória quanto ao monitoramento eletrônico.

De igual sorte, o regulamento interno da empresa pode conter previsões acerca do monitoramento dos meios eletrônicos com vista a garantir maior segurança às partes, levando ao conhecimento dos empregados os procedimentos a serem observados no desempenho do serviço, os direitos e deveres das partes envolvidas e os limites quanto à utilização do e-mail no ambiente laboral.

0 estabelecimento de um regulamento interno para disciplinar a questão do monitoramento no espaço intra-empresarial constitui-se em prerrogativa do poder diretivo do empregador. Porém, as cláusulas nele inseridas não podem contrariar a Constituição, a lei, as normas legais de proteção ao trabalho, a moral, os bons costumes e as normas coletivas, salvo se estabelecerem melhores condições ao empregado.

Assim, ao lado das negociações coletivas, o regulamento interno também se mostra como um instrumento apropriado para regulamentar, por meio de cláusulas que aderem ao contrato individual de trabalho, condições específicas da atividade laboral em observância às exigências e peculiaridades de cada empresa (GOM ES; GOTTSCHALK, 2007, p. 53).

\section{Política Empresarial de Utilização dos M eios Eletrônicos}

Como já visto, a questão do gerenciamento eletrônico pode regida por meio de norma coletiva, regulamentação interna ou política empresarial integrante do contrato individual de trabalho. 
A instituição de uma política de utilização e monitoramento de e-mail e acesso à internet que trace diretivas claras e objetivas quanto ao seu uso pelos empregados constitui como uma das formas de conciliar os direitos fundamentais do trabalhador com os direitos de propriedade e direção do empregador.

Essas diretivas devem estabelecer as regras e limites para o uso do e-mail e da internet, como também deixar claro que o uso do equipamento de comunicação se limita ao exercício das funções do empregado na empresa, explicitar o que é aceitável ou não como conduta, suas responsabilidades, sanções em caso de violação e deveres quanto ao sigilo dos dados e documentos que se têm acesso (CALVO, 2003).

Conquanto devam observar o disposto no contrato individual de trabalho ou nas convenções coletivas aplicáveis, as diretivas têm como finalidade primordial estabelecer limites sobre o uso dos meios eletrônicos em serviço e enumerar as condutas que os empregados e empregadores devem se abster, de modo a alertar o empregado sobre as conseqüências do uso inadequado dos equipamentos de informática disponibilizados pela empresa (ROCHA, 2004, p. 173-175).

Nessa política de conscientização, recomenda-se que o empregador deixe consignado nas diretivas a tolerância acerca do uso eventual e razoável do correio eletrônico corporativo e da internet para fins particulares (ROCHA, 2004, p. 174-175).

Atenta-se também, para a necessidade de que os empregados e terceiros que com eles se comunicam sejam avisados sobre a existência da política e das diretivas que tratam do controle dos correios eletrônicos, aconselhando-se que sejam lembrados sobre 0 monitoramento através de mensagens na tela do computador que "além de informar exija a confirmação de que o empregado recebeu a mensagem, que entendeu 0 aviso, que tem conhecimento da política da empresa e está de acordo" (ROCHA, 2004, p. 174).

Vale lembrar que embora essa política não se constitua como medida absoluta, ela serve como meio de propiciar um acesso seguro aos equipamentos de informática da empresa pelos trabalhadores, auxiliando na solução dos conflitos advindos e impondo limites às partes através de um equilíbrio entre segurança e privacidade (ROCHA, 2004, p. 176).

Enfim, o ideal seria que houvesse uma reestruturação do ordenamento jurídico, a exemplo da Grã- Bretanha e Holanda que já possuem regulamentação acerca do 
monitoramento, adequando-o às questões oriundas do uso das novas tecnologias de informática (ROCHA, 2004, p. 153). No entanto, a carência de regra disciplinadora a respeito faz com que o monitoramento eletrônico seja balizado por meio de negociações coletivas, políticas empresariais de uso e regulamento interno.

\section{Conclusão}

A globalização, as novas tecnologias de informática, a sociedade de informação, a conexão à distância e a instalação de um ambiente de trabalho virtual são os principais protagonistas das questões jurídicas que têm surgido quanto ao uso da internet e do correio eletrônico pelos empregados no meio laboral.

A par das preocupações que fundamentam o rastreamento pelo empregador, não é menos importante a proteção do empregado quanto a sua dignidade, privacidade, intimidade e sigilo das comunicações, ainda mais pelo fato da correspondência eletrônica assemelhar-se à postal .

Ao lado dessa colisão de direitos, que ora abrange o poder diretivo e ora, a privacidade do empregado, é prudente que se apliquem os critérios de pacificação princípio da proporcionalidade, da ponderação de bens, da concordância prática e da máxima observância e da mínima restrição - para harmonizar os interesses envolvidos.

É evidente que o empregador, no exerć́cio do seu poder diretivo, pode permitir o uso do correio eletrônico corporativo para fins alheios ao serviço, bem como limitar, proibir ou restringir a utilização da internet e do e-mail particular durante ou fora da jornada de trabalho.

Todavia, o poder patronal não se configura como um direito absoluto e justificador de arbítrios. Ao contrário, o seu exercício deve observar os limites impostos pelos direitos fundamentais e pela razoabilidade de modo que o empregador exerça um padrão razoável de vigilância quanto aos meios de comunicação, priorizando pelos instrumentos de controle menos intrusivos, adequando para tanto o meio utilizado aos fins pretendidos.

0 e-mail corporativo configura-se como ferramenta de trabalho colocada à disposição do empregado para uso estritamente profissional, estando sujeito a um controle formal e até mesmo material nos casos em que haja indícios objetivos de mau uso do equipamento eletrônico, fazendo-se necessária a comunicação prévia ao afetado e a 
participação de um representante sindical, se possível.

Já, o e-mail particular, por estar inserido na esfera íntima do indivíduo, pode se submeter a um controle meramente formal. Contudo, em razão de circunstâncias relevantes e através de prévia autorização judicial ou do próprio empregado, livre de coações, pode 0 conteúdo pessoal das mensagens eletrônicas ser interceptado por interpretação extensiva do artigo 50, inc. XII da CF.

Lembre-se que a prova obtida através de uma intromissão não autorizada no correio eletrônico particular do trabalhador é vedada pelo ordenamento jurídico, que não admite no processo as provas obtidas por meio ilícito (art. 50, inc. LVI CF). Todavia, há situações excepcionais, além do estado de necessidade, em que a prova, a despeito de ser ilícita, deve ser aceita em prol de uma finalidade legítima e justificável.

Ademais, não assiste ao empregador o poder de restringir em absoluto a comunicação externa do empregado, inclusive no tocante aos assuntos de natureza sindical. Porém nada impede que 0 uso do e-mail e da internet para esse fim seja feita de forma moderada, em horário compatível e de modo a preservar o bom andamento do serviço, sendo que os eventuais exageros devem ser reprimidos disciplinarmente, inclusive por meio de dispensa por justa causa.

Enfim, o ideal seria a positivação do tema para garantir uma maior segurança nas relações empregatícias, sobretudo nos aspectos que envolvem o gerenciamento eletrônico. No entanto, ante à inexistência de regulamentação sobre o assunto, é importante que os conflitos envolvendo direito de vigilância, internet e privacidade do empregado, sejam dirimidos por meio de negociação coletiva de trabalho, regulamento interno da empresa ou políticas de conscientização empresarial que discipline o uso da internet e do correio eletrônico no meio laboral.

\section{Referências}

ARARIPE, Jales de Alencar. Direitos da personalidade: uma introdução. In: LOTUFO, Renan (Coord.). Direito Civil Constitucional. São Paulo: M alheiros, 2002. Caderno 3, p. 211-235. 
ATHENIENSE, Alexandre. 0 monitoramento eletrônico e as relações trabalhistas. Disponível em:http://209.85.173.104/search?q=cache:zu30shFGuTc):www.ambitojuridico.com.br/site/ index.php\%3Fn_link\%3Drevista_artigos_leitura\%26artigo_id\%3D2382+\%3Chttp://www.amb itojuridico.com.br/site/index.php\%3Fn_link\%3Drevista_artigos_leitura\%26artigo_id\%3D238 $2 \% 3 E . \& h l=p t-B R \& c t=c \mid n k \& c d=1>$. Acesso em: 27 abr. 2008.

BARROS, Alice M onteiro de. Curso de direito do trabalho. 3.ed. São Paulo: LTr, 2007.

BELM ONTE, Alexandre Agra. 0 monitoramento da correspondência eletrônica nas relações de trabalho. São Paulo: LTr, 2004.

BELTRAN, Ari Possidonio. Direito do trabalho: limites do poder diretivo e outras questões da atualidade. Revista do Advogado: Direito do Trabalho Questões Atuais, AASP (Associação dos Advogados de São Paulo), v. 25, n. 82, p.10-20, jun. 2005.

BONSOR, Kevin. Como funciona a supervisão no local de trabalho. Disponível em: বhttp://informatica.hsw.uol.com.br/supervisao-no-local-de-trabalho3.htm>. Acesso em: 5 abr. 2008.

CALVO, Adriana Carrera. 0 uso indevido do correio eletrônico no ambiente de trabalho. Disponível em: «ttp:// jus2.uol.com.br/doutrina/texto.asp?id=6451>. Acesso em: 15 dez. 2007.

CAPEZ, Fernando. Processo penal. 15.ed. São Paulo: Damásio de Jesus, 2006.

CARNEIRO, Joana Zago. 0 monitoramento dos e-mails corporativos à luz dos princípios constitucionais. Revista do Direito do Trabalho, São Paulo, v. 33, n. 127, p. 84-100, jul./set. 2007.

CLÈVE, Clémerson M erlin; FREIRE, Alexandre Reis Siqueira. Algumas notas sobre colisão de direitos fundamentais. In: GRAU, Eros Roberto; CUNHA, Sérgio Sérvulo da (Coord.). Estudos de Direito Constitucional em homenagem a José Afonso da Silva. São Paulo: Malheiros: 2003, p. 231-243.

DELGADO, Maurício Godinho. Curso de direito do trabalho. 6.ed. São Paulo: LTr, 2007.

DUARTE, Juliana Bracks; TUPINAM BÁ, Carolina. Direito à intimidade do empregado $X$ direito de propriedade e poder diretivo do empregador. Revista de Direito do Trabalho, São Paulo, v. 28, n. 105, p.231-243, jan./mar. 2002.

ESPÍNDOLA, Ruy Samuel. Conceito de princípios constitucionais. 2.ed. São Paulo: Revista dos Tribunais, 2002. 
FERRARI, Irany. Legislado X Negociado uma alternativa na solução de conflitos. Revista do Tribunal Regional do Trabalho da 15a Região, Campinas, n. 17, p. 41-42, 2001.

FERREIRA, Ana Amélia Menna Barreto de Castro. Correio eletrônico corporativo - Aspectos jurídicos. Revista de Direito do Trabalho, São Paulo, v. 29, p.13-29, abr./jun. 2003.

FERREIRA, Aurélio Buarque de Holanda. Aurélio Século XXI: o dicionário da língua portuguesa. 3 ed. Rio de Janeiro: Nova Fronteira, 1999.

GOM ES, Orlando; GOTTSCHALK, Elson. Curso de direito do trabalho. 18.ed. Rio de Janeiro: Forense, 2007.

LEALJÚNIOR, João Carlos; GALLINA, Paolla M aria. M onitoramento do correio eletrônico do obreiro pelo empregador em ambiente de trabalho. Disponível em:

বhttp://www.direitonet.com.br/artigos/x/38/62/3862/ >. Acesso em: 10 dez. 2007.

M ARTINS, Sérgio Pinto. Direito do trabalho. 23.ed. São Paulo: Atlas, 2007.

M ISTRONGUE, Alessandra Loyola; KERSTEN, Felipe de Oliveira. Invasão de Privacidade: a violação de e- mails nas relações de trabalho à luz da ordem jurídico-constitucional brasileira. Revista LTr, São Paulo, v. 68, n. 3, p. 310-322, mar. 2004.

NASCIM ENTO, Amauri M ascaro. Curso de direito do trabalho. 19.ed. São Paulo: Saraiva, 2004.

OLIVEIRA, Euler Sinoir de. A inconstitucionalidade da violação de e-mail do empregado pelo empregador. Revista do Tribunal Regional do Trabalho 9a Região, Curitiba, v. 30, n. 55, p. 231-254, jul./dez. 2005.

PAIVA, Mário Antônio Lobato de. 0 monitoramento do correio eletrônico no ambiente de trabalho. Disponível em: «ttp:// jus2.uol.com.br/doutrina/texto.asp?id=3486>. Acesso em: 13 dez. 2007.

PEREIRA, Marcelo Cardoso. Direito à intimidade na internet. Curitiba: Juruá, 2004.

ROCHA, M arcelo Oliveira. Do monitoramento dos e-mails no ambiente de trabalho. São Paulo: Paulistanajur, 2004.

SILVEIRA NETO, Antônio; PAIVA, Mário Antônio Lobato de. A privacidade do trabalhador no meio informático. Revista de Direito do Trabalho, São Paulo, v. 29, n. 111, p. 13-26, jul./set. 2003. 
SOUZA, M auro César M artins de. E-mail (...net) na relação de emprego: poder diretivo do empregador (segurança) \& privacidade do empregado. Disponível em:

বttp://kplus.cosmo.com.br/matéria.asp?co=46\&rv=Direito >. Acesso em: 10 dez. 2007. 